\title{
A User-Oriented Implementation of Risk Breakdown Structure in Construction Risk Management
}

\author{
Julinda Keci
}

Department of Civil Engineering, Epoka University, Tirana 1039, Albania

\begin{abstract}
The construction industry works under conditions of uncertainties and risks leading to poor performance, increased cost and time and decreased quality. In these conditions, the dynamic identification and assessment of project risks among a vary range of potential factors is considered of vital importance. The introduction of RBS (risk breakdown structure) as a hierarchically organized depiction of identified risks was considered a suitable tool in risk management, especially in construction, due to its many advantages in synthetic representation and dynamic nature. This paper presents a user-oriented implementation of RBS to assist the project managers in identifying and assessing potential risk factors affecting construction process. The evidential analogies between WBS (work breakdown structure) and RBS are captured and used in the proposed framework which interconnects them into a 2D (two dimensional) matrix used to associate risks to the specific project activities. The proposed framework is applied to a government funded design-bid-build project. The obtained results clearly demonstrate the advantages in identifying the most risky activities, as well as the most important risk factors affecting the whole project.
\end{abstract}

Key words: Construction risk, RBS, user-oriented approach, 2D matrix, WBS.

\section{Introduction}

Construction projects are complex activities involving many participants with different objectives. They are generally considered as long term projects subjected to a vary range of risks and uncertainties during their life cycle.

According to Chan and Kumarasawamy [1], a project is considered "successful" if it is completed on time, within budget and on the specific quality standards. In practice, it is well known that projects tend to exhibit cost overruns and schedule delays, causing failures and leading to collapses. Owing to its increasing importance, risk management has been recognized as a necessity in most industries today, and a set of techniques have been developed to control the influences brought by potential risks [2]. In these conditions, the application and improvement of project risk management becomes of vital importance, and it is also a key challenge for scientific research.

Corresponding author: Julinda Keci, Ph.D. student, research fields: construction management and risk management, construction planning. E-mail: jkeci@epoka.edu.al.
The modification of key risks during the project progress requires an iterative risk management process carried out during the life cycle and considering the specific project objectives and circumstances.

There is a large number of scientific researches on risk management techniques, involving different steps such as: risk identification, risk assessment, risk response, and monitoring and controlling. A variety of tools and techniques can be used to identify possible risks that could affect construction projects. However, these tend to produce an unstructured list of risks that often does not direct the manager in knowing where to focus the managerial attention [3]. In order to help prioritizing the identified risks are used qualitative assessments, but they suffer several drawbacks in not considering the patterns of risk exposure.

In large sized, complex projects where a lot of data are produced, a hierarchical structure is an essential strategy. The most evident illustration of the value of structuring within project management is the WBS 
(work breakdown structure), which is recognized as a major engine for the project manager because it provides a mean to structure the work to be done in order to accomplish the project objectives. Similar to this, using RBS (risk breakdown structure) is a very practical tool, simplifying and supporting the management process in the later stages. According to Hillson [3], following the pattern of WBS definition stated in PMI (Project Management Institute) [4], RBS is defined as "a source-oriented grouping of project risks that organizes and defines the total risk exposure of the project. Each descending level represents increasing detailed information of risk sources to the project". However, it has been recognized that risk breakdown structure suffers from several deficiencies such as lack of clarity on how to develop it for new projects according to their specific needs and objectives, inconsistencies in definition of risk categories and difficulties in transferring the qualitative/quantitative assessment of risk across the structure [5]. According to Mehdizadeh et al. [6], in general there is no clear definition of the meaning of risk categories and the same words can cover different items in different project activities.

This research aimed to develop a user-oriented approach for risk breakdown structure implementation linking WBS to RBS in order to produce a combined framework helping in the identification and assessment stage and providing support in further stages. This methodology can provide useful information in identifying:

- which activities have many associated risks;

- the most important risk factors affecting the whole project;

- the most significant risks' relationships.

Thus, the specific objectives and methods used in this research are as follows:

- the development of a user oriented RBS-WBS;

- the development of a consistent assessment approach adapted to several criteria: fitting different project development stages, offering different views, highlighting the most important relationships.

\section{Risk and Risk Management Process}

Construction projects are complex, involving a wide set of tasks to be conducted within resources constraints and future uncertainties to meet defined objectives. It has been known for a long time that due to a wide range of possible risks projects tend to exhibit cost overruns, schedule delays and quality decrease.

Project risk has been defined as a multi face concept. It can be expressed as "the potential for unwanted or negative consequences of an event or activity" [7], "a threat and a challenge" [8], "a combination of probability of an event occurring and its consequences for project objectives" $[9,10]$.

According to PMBOK of PMI [11], risk includes upside effects, the opportunities, but traditionally focuses on the downside, i.e., the negative effects. A review of risks definitions leads to the following faces of project risk: an event that focuses on the future, emphasizes the negative effects, deals with the probability and consequences [12]. The level of risks varies from project to project and is directly related to the project context and content. In these conditions, a dynamic risk management is a key element and has been continuously examined from 1978.

"Risk management is one of those ideas that sense that a logical, consistent and disciplined approach to the future's uncertainties will allow us to live with them prudently and productively, avoiding unnecessary waste of resources. It goes beyond faith and luck, the twin pillars of managing the future before we began learning how to measure probability" [13].

A variety of risk management techniques have been studied and introduced in the literature: Berkeley et al. [14] and Flanagan and Norman [8] categorized the process of risk management into: risk classification, risk identification, risk analysis and risk response, as shown in Fig. 1. Project Management Body of Knowledge [11] introduced a five steps procedure 


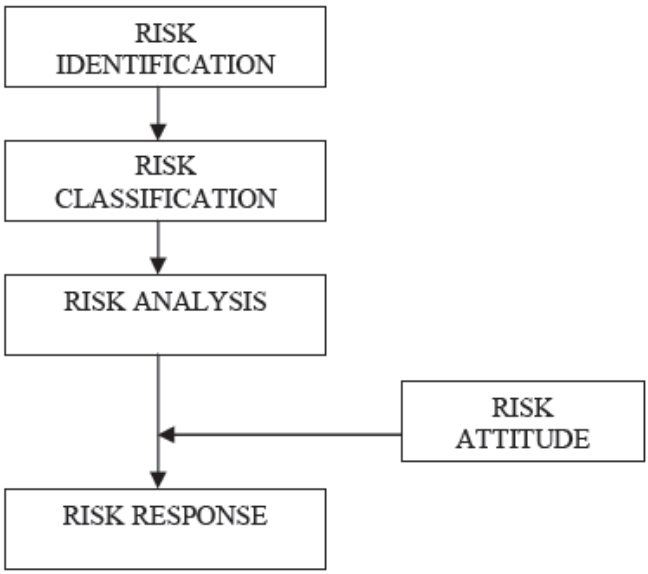

Fig. 1 The risk management framework [8].

including planning, identification, qualitative assessment, quantitative assessment, response planning, while Baloi and Price [15] included an additional step of risk communication. The Australian and New Zealand Standard [16, 17] illustrated five steps procedure interconnected to each other, as shown in Fig. 2.

Similar to this approach, Baker et al. [18] have suggested fitting the five steps in a simple circular procedure which will yield a controlled risk environment. Wang et al. [19], in their study about risk management framework for construction projects in developing countries, proposed a risk model, called Alien Eyes Risk Model showing the three risk hierarchy levels and the impact connection between risks. Zhou and Zhang [20] proposed a dynamic risk management system for big sized construction projects in China, composed of six main parts, namely event database, risk tracking, risk pre-control, risk assessment, risk identification and risk database. Despite the wide variety of the techniques, they have common objectives: identification of risk sources, their assessment and treatment.

\section{Risk Breakdown Structure}

\subsection{Introduction of $R B S$}

Using traditional RM (risk management) techniques enables the identification of the project risks, which can be prioritized in the assessment phase to determine the risks which should be addressed first. There is an extensive literature focusing on the risk identification process evaluating the most frequently used tools, their strengths and weaknesses, as shown in Table 1. Based on a study made by Keci and Oztas [12], the most frequent identification tools used in Albanian construction industry were brainstorming, Delphi technique, check list and questionnaire.

However, in big sized projects, the traditional identification tools will tend to produce unstructured lists of risks. Based on the WBS concept introduced by PMI [4], the hierarchical structure of risks is a very practical tool.

Cano and Cruze [21] decomposed the project into four phases (initiation, balancing, maintenance and learning), developing them into sub-phases, activities and sub-activities. Chapman [22] proposed to set up a systematically RBS (risk breakdown structure), to

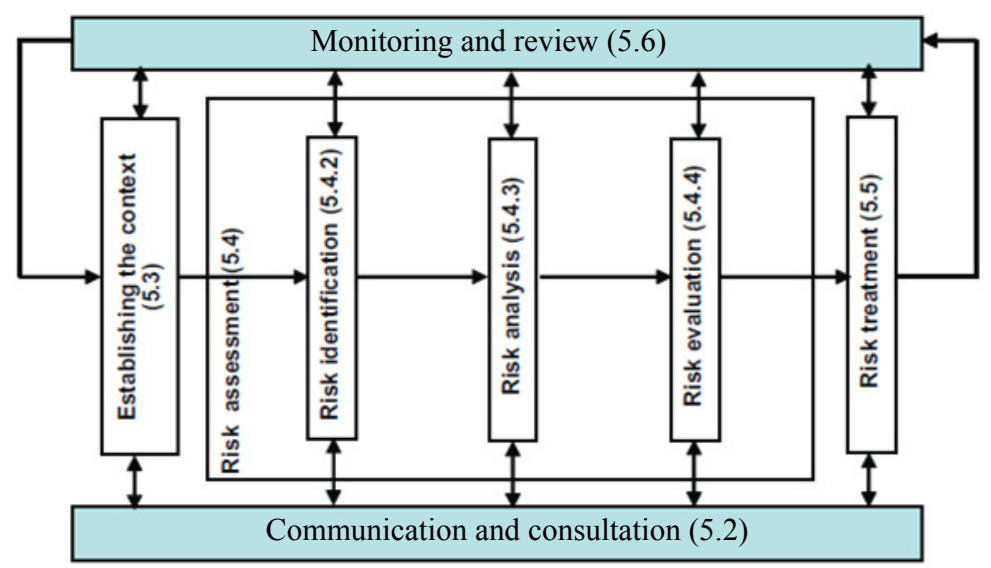

Fig. 2 The risk management process according to The Australia and New Zealand Standard on Risk Management [16, 17]. 
Table 1 Risk identification tools: strength and weakness [29].

\begin{tabular}{|c|c|c|c|}
\hline Technique & Strength & Weakness & Authors \\
\hline Brainstorming & $\begin{array}{l}\text {-Allows all participants to speak } \\
\text { their mind and contribute to the } \\
\text { discussion } \\
\text {-Can involve all key stakeholders } \\
\text {-Creative generation of ideas }\end{array}$ & $\begin{array}{l}\text {-Requires attendance of key stakeholders at a } \\
\text { workshop, therefore can be difficult to arrange } \\
\text { and expensive } \\
\text {-Prone to groupthink and other group dynamics } \\
\text {-May produce biased results if dominated by a } \\
\text { strong person (often management) } \\
\text {-Often not well facilitated } \\
\text {-Generates non-risks and duplicates, requires } \\
\text { filtering }\end{array}$ & $\begin{array}{l}\text { Chapman [30] } \\
\text { Baker et al. [18] } \\
\text { Akintoye and MacLeod [31] } \\
\text { Hlaing et al. [32] }\end{array}$ \\
\hline Delphi technique & $\begin{array}{l}\text {-Captures input from technical } \\
\text { experts } \\
\text {-Removes sources of bias }\end{array}$ & $\begin{array}{l}\text {-Limited to technical risks } \\
\text {-Dependent on actual expertise of experts } \\
\text {-May take longer time than available due to } \\
\text { iterations of the experts' inputs }\end{array}$ & Chapman $[22,30]$ \\
\hline Check list & $\begin{array}{l}\text {-Captures previous experience } \\
\text {-Presents detailed list of risks }\end{array}$ & $\begin{array}{l}\text {-Check list can grow to become unwieldy } \\
\text {-Risks not on the list will be missed } \\
\text {-Often only includes threats, misses } \\
\text { opportunities }\end{array}$ & $\begin{array}{l}\text { Akintoye and MacLeod [31] } \\
\text { Simister [33] } \\
\text { Hlaing et al. [32] }\end{array}$ \\
\hline Questionnaire & $\begin{array}{l}\text {-Encourages broad thinking to } \\
\text { identify risks }\end{array}$ & $\begin{array}{l}\text {-Success depends on the quality of the } \\
\text { questions } \\
\text {-Limited to the topics covered by the questions } \\
\text {-Can be a simple reformatting of a checklist }\end{array}$ & $\begin{array}{l}\text { Simister [33] } \\
\text { Hlaing et al. [32] }\end{array}$ \\
\hline
\end{tabular}

facilitate the identification process. The usage of RBS, with as many levels as required, gained a great importance as a better solution for management purposes.

A wide range of RBS have been produced under various project objectives and there is no identified "standard practice" for RBS development. Many classifications have been developed over the years, however, most of them have considered the source criteria as the most important [23]. Other classifications made are according to their origin: internal and external risks [24, 25], according to their magnitude: primary and secondary risks [26], according to the project phases [27], according to their importance [28], according to the stakeholders [5], etc.. Other common categorizations are: internal and external, positive and negative, dynamic and static, corporate and individual, etc..

\subsection{Development of $R B S$}

Different RBS approaches have been adapted to the specific projects requirements highlighting the need for the development of a dynamic tailored based RBS. However, there are interactive components helping in RBS development defined from the literature as follows:

- RE (risk event): is considered a future event which has a probability of occurrence and some consequences on project objectives;

- RC (risk category): is a grouping of several RE communed by a specific characteristic;

- MT (micro tree): is defined as the decomposition of RC into subcategories.

According to Mehdizadeh [5], each RBS is viewed as a set of micro trees in which each "son" RC can be further decomposed, as long as it is a father node in another MT.

\subsection{Benefits from RBS}

The RBS is a hierarchical structure that represents the overall project and organizational risk factors and events organized by groups and categories [34]. It offers a variety of benefits not only in identification phase, offering a synthetic view on risk, but also supporting further stages: 
(1) Risk identification: beside being used as a simple check list, it gives a general overview to ensure a complete coverage by mapping identified risks in each category;

(2) Risk assessment: identified risks are assessed by allocating them to the specific areas. According to Hillson et al. [35] assessing risks using RBS provides an additional insight into:

- understanding the type of risk exposure;

- exposing the most significant risk sources;

- reveling root causes of risks;

- indicating areas of dependency or correlations between risks, etc.;

(3) Risk reporting: rolling up or drilling down to report information according to specific requirements;

(4) Dynamic tailored-based RBS: it can be reduced or broadened, in depth or in breadth [34], to meet various special requirements according to the level of information available creating in this way an iterative, dynamic system;

(5) Lessons for future projects: due to its structured information, it can be used as reference for future projects, or as a comparison tool for parallel projects.

Generally, the scientific research has been focused on the benefits of RBS in the identification phase, underestimating the other strengthens.

In this study, a user-oriented approach for risk breakdown structure implementation linking WBS to RBS was presented, in order to produce a combined framework helping in the identification and assessment stages, and providing support in further phases.

\section{Linking WBS to RBS}

The evident analogies between WBS and RBS make it possible to interconnect them into a useful technique associating risks to the specific project activities. Considering the advantages of RBS as a risk identification technique, its combination with WBS would have several additional powerful strengths in:
- offering a synthetic view on risks affecting each work package;

- providing perspectives of where are risks coming from and concentrated at [6];

- recognizing the most risky work items (WP);

- each stakeholder can have his own view on the project activities;

- being compatible with the dynamic nature of construction project risks;

- successfully over passing the identified deficiencies of RBS [6] that there is no clear definition on the meaning of risk categories and the same words can cover different items in different project activities.

To generate the combined methodology, first the identification process using RBS with as many hierarchical levels as required is performed. The lowest levels of RBS are then interconnected with the lowest levels of WPS, creating a type of 2D matrix. The risk values are calculated by multiplying the probability of that risk to happen $\left(P_{i, 1}\right)$ with its impact on the specific WP in case of occurrence $\left(I_{1, j}\right)$. The assessment of $P_{i, l}$ and $I_{l, j}$ is made based on a cardinal scale approach.

The amount obtained by summing each cell in the rows of the matrix table gives us the value of each risk factor on the overall project. By this approach, it can be evaluated the level of criticality for each risk, in absolute terms or in relative to each other. With a similar reasoning, the amount obtained by summing each cell of the columns gives us the value of the risk embraced in each WP. Based on the performed assessment, we choose the appropriate response techniques.

The example of WBS adopted for this application is the case of a governmental design-bid-build project developed in PMI [29]. The WBS is structured according to the project phases (Fig. 3), and the RBS is structured according to risk sources (Fig. 4). Both WBS and the developed RBS have three levels. 


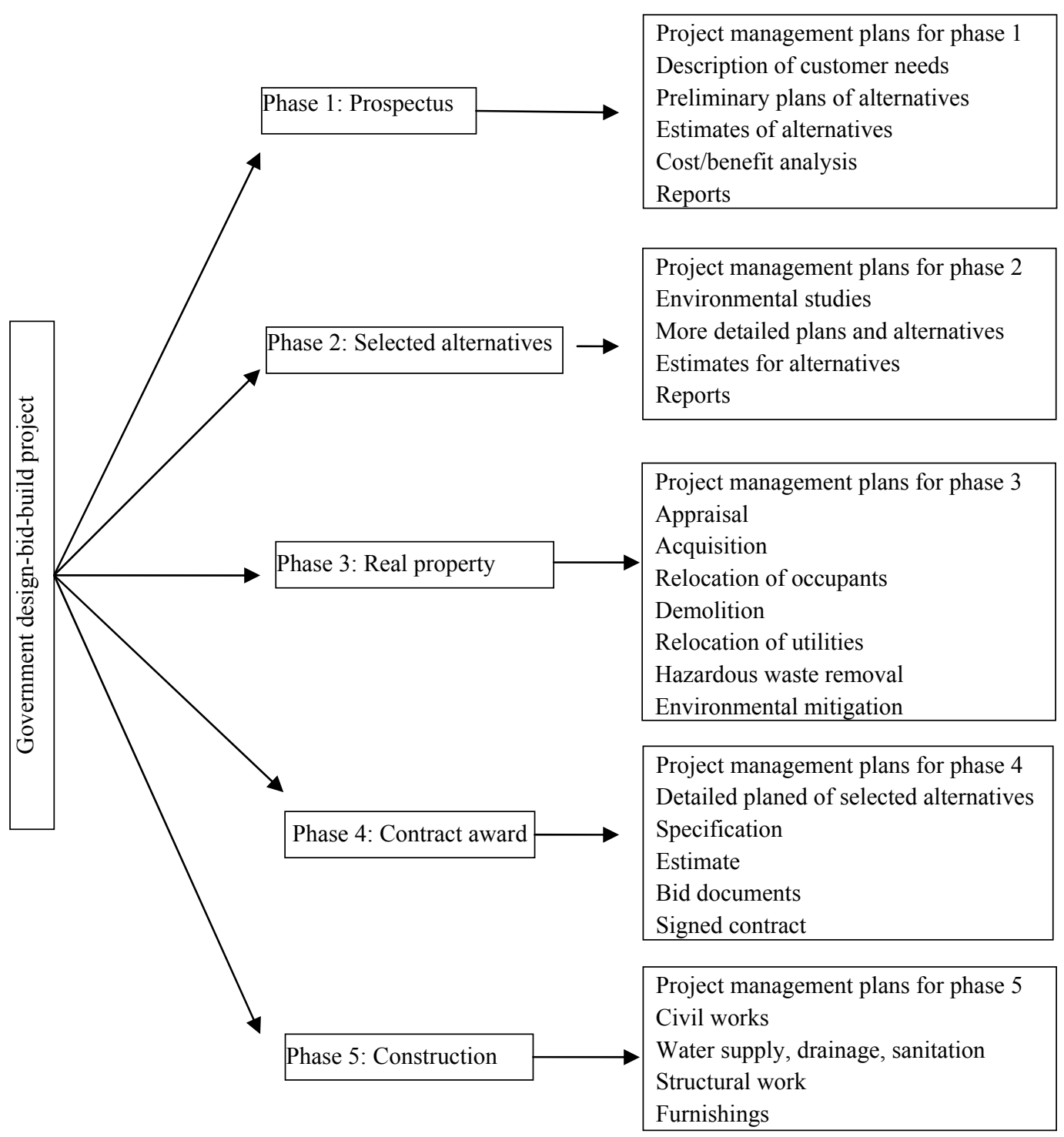

Fig. 3 WBS for a government funded design-bid-build project.

The lowest levels of WPS and risk sources will be considered while applying the combination, forming a $2 \mathrm{D}$ matrix $30 \times 27$, as shown in Table 2. For simplicity reasons, only one branch of WBS combination with RBS will be shown.

To assess the risk affecting each work item, five construction managers were asked to express their opinion on a scale 1 to 5 , applying two-dimensional scaling, the probability of recognized risk factors in case of happening as well as their expected consequences on project based on Table 3. Results are presented in Table 4.
These considerations allow us identify which activities have more associated risks, the most important risk factors affecting the whole project, as well as the most significant relationships. As seen in Table 4, "Structural Works" is evaluated as the most critical activity, followed by "Planning" and "Civil Works". Furthermore, "Lack of Management Experience", "Financial Constraints" and "Lack of Organizational Experience" resulted to be the most critical risk factors. Special attention must be paid to the relationship between planning and management experience, which results to have the highest risk value. 


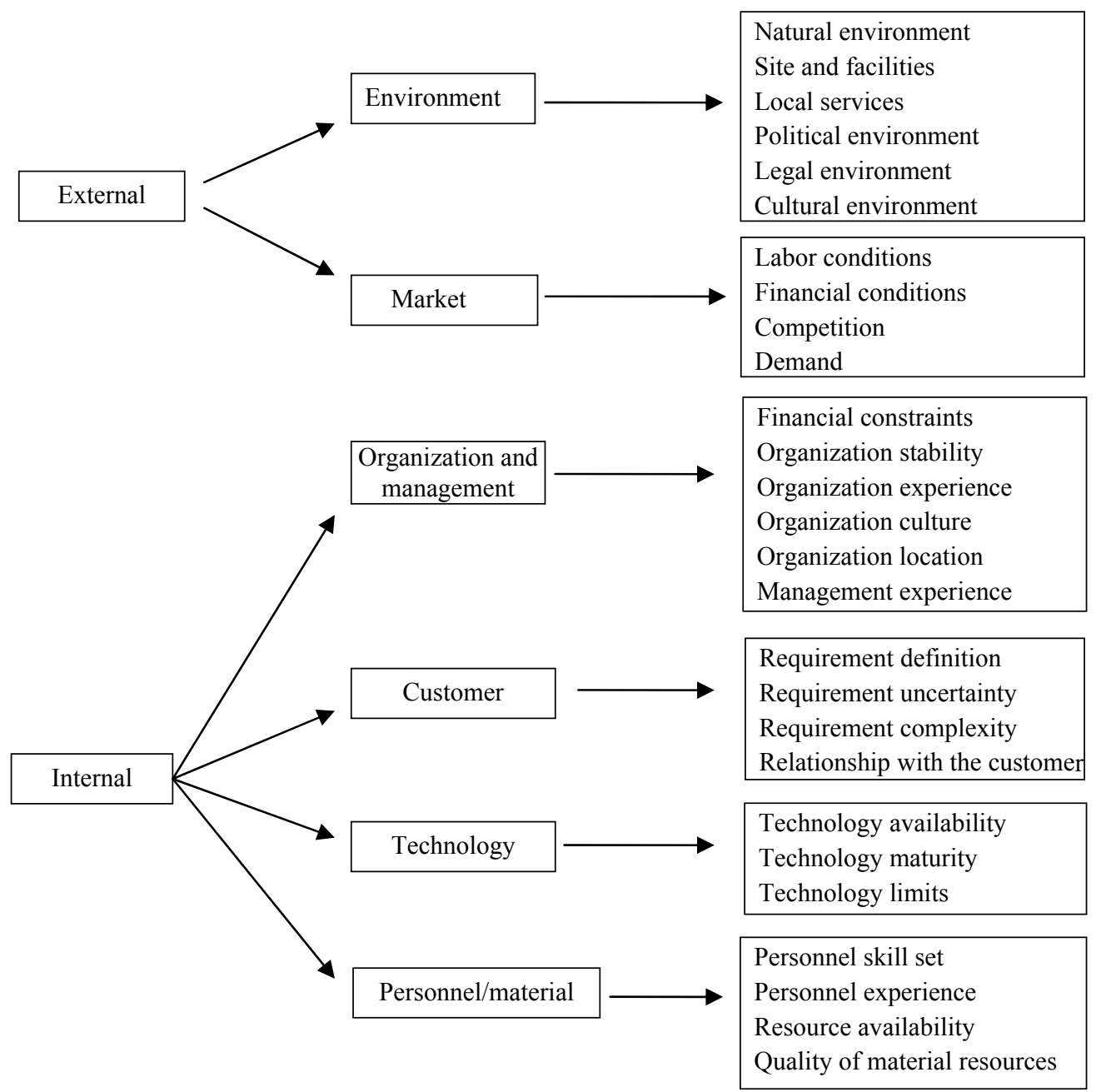

Fig. 4 RBS framework for a government funded design-bid-build project.

Table 2 Creation of 2D matrix, linking RBS to WBS

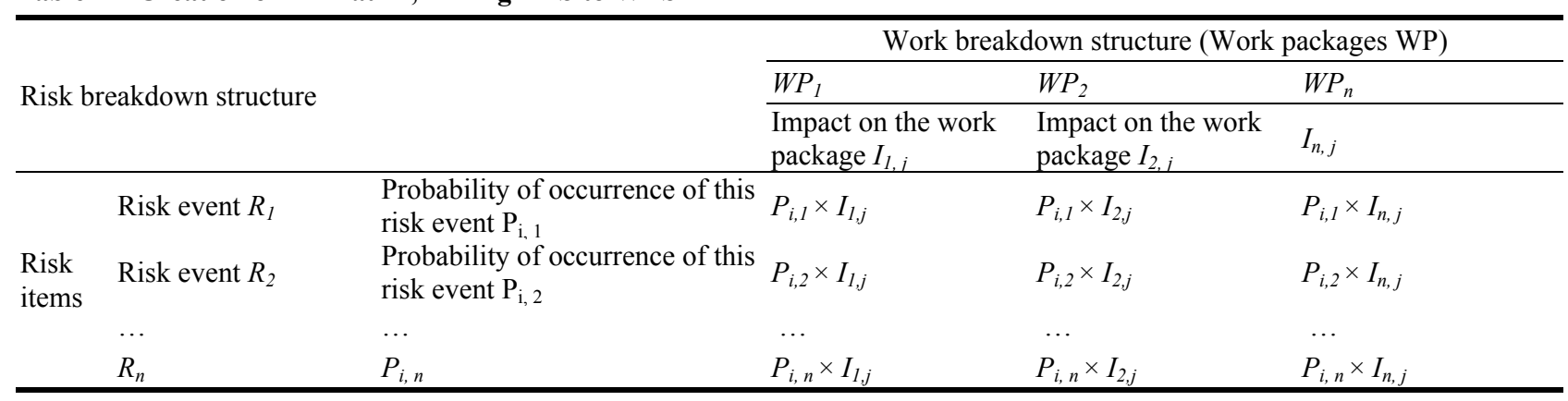

Based on this assessment, the response technique will be taken adequately. The dynamic tailored-based nature of the combination RBS-WBS will help in the monitoring and controlling phase by reducing or broadened, in depth or in breadth [34], to meet various special requirements according to the level of information available.

\section{Conclusions}

The construction projects embrace two main areas of difficulties: the complexity of the projects itself and the risks that could affect them. In these conditions, a successful and effective implementation of risk management tools and techniques becomes 
Table 3 Likelihood and consequences of risk factors.

\begin{tabular}{llllll}
\hline No. & Likelihood & Description & No. & Likelihood & Description \\
\hline 1 & Very low & The occurrence is not anticipated & 1 & Insignificant & Minor/negligible impact \\
2 & Low & Trivial likelihood however could occur & 2 & Minor & Trivial/small impact \\
3 & Medium & Possibility less than 50-50 & 3 & Moderate & Moderate/reasonable \\
4 & High & Possibility more than 50-50 & 4 & Major & Critical danger \\
5 & Very high & Almost certain it would occur & 5 & Catastrophic & The effect is completely undesirable \\
\hline
\end{tabular}

Table 4 Combined RBS and WBS matrix for the case study.

\begin{tabular}{|c|c|c|c|c|c|c|c|c|c|}
\hline \multirow[b]{2}{*}{ RBS } & & & \multicolumn{5}{|c|}{ WBS (Phase 5: Construction) } & \multirow[b]{2}{*}{$\sum R$} & \multirow[b]{2}{*}{ Order } \\
\hline & & & $\begin{array}{l}\text { Planning } \\
\text { impact }\end{array}$ & $\begin{array}{l}\text { Civil works } \\
\text { impact }\end{array}$ & $\begin{array}{l}\text { Water supply, } \\
\text { derange impact }\end{array}$ & $\begin{array}{l}\text { Structural works } \\
\text { impact }\end{array}$ & $\begin{array}{l}\text { Furnishing } \\
\text { impact }\end{array}$ & & \\
\hline \multirow{6}{*}{$\begin{array}{l}\text { Organization } \\
\text { and } \\
\text { management }\end{array}$} & $\begin{array}{l}\text { Financial } \\
\text { constraints }\end{array}$ & Probability & $\begin{array}{l}P=2, \mathrm{I}=3 \\
R=6\end{array}$ & $\begin{array}{l}P=4, I=4 \\
R=16\end{array}$ & $\begin{array}{l}P=2, I=2 \\
R=4\end{array}$ & $\begin{array}{l}P=4, I=5 \\
R=20\end{array}$ & $\begin{array}{l}P=4, I= \\
3 \\
R=12\end{array}$ & 58 & 2 \\
\hline & $\begin{array}{l}\text { Organization } \\
\text { Stability }\end{array}$ & Probability & - & - & - & $\begin{array}{l}P=2, \mathrm{I}=2 \\
R=4\end{array}$ & - & 4 & 5 \\
\hline & $\begin{array}{l}\text { Organization } \\
\text { experience }\end{array}$ & Probability & $\begin{array}{l}P=3, I=4 \\
R=12\end{array}$ & $\begin{array}{l}P=2, I=2 \\
R=4\end{array}$ & - & $\begin{array}{l}P=3, I=4 \\
R=12\end{array}$ & - & 27 & 3 \\
\hline & $\begin{array}{l}\text { Organization } \\
\text { culture }\end{array}$ & Probability & 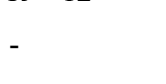 & $\begin{array}{l}P=2, I=2 \\
R=4\end{array}$ & - & $\begin{array}{l}\mathrm{P}=2, \mathrm{I}=2 \\
\mathrm{R}=4\end{array}$ & - & 8 & 4 \\
\hline & $\begin{array}{l}\text { Organization } \\
\text { location }\end{array}$ & Probability & - & $\begin{array}{l}P=1, I=2 \\
R=2\end{array}$ & - & 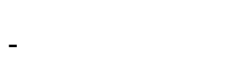 & - & 2 & 6 \\
\hline & $\begin{array}{l}\text { Management } \\
\text { Experience }\end{array}$ & Probability & $\begin{array}{l}P=5, I=5 \\
R=25\end{array}$ & $\begin{array}{l}P=3, I=5, \\
R=15\end{array}$ & $\begin{array}{l}P=3, I=4 \\
R=12\end{array}$ & $\begin{array}{l}P=2, I=3 \\
R=6\end{array}$ & $\begin{array}{l}P=2, I= \\
3 \\
R=6\end{array}$ & 64 & 1 \\
\hline \multicolumn{2}{|l|}{$\overline{\sum R}$} & & 43 & 41 & 16 & 46 & 18 & & \\
\hline \multicolumn{2}{|l|}{ Order } & & 2 & 3 & 5 & 1 & 4 & & \\
\hline
\end{tabular}

indispensable for reaching the project objectives. The developed combination RBS-WBS assist managers in both areas offering a dynamic, multi-scale and multi-perspective project risk identification tool.

The combined matrix generated for the case adopted helped on:

(1) offering a synthetic view on the key risks affecting each activity;

(2) recognizing the most risky work items (WP);

(3) providing an overview of the risk provenance, as well as its concentration;

(4) providing a dynamic representation by being synthesized or broadened according to the level of information available and to the focus required.

The compatible methodology with the dynamic nature of construction project risks and the successfully overpass of the identified RBS deficiencies gives to this methodology clear benefits for a user-oriented implementation.

\section{References}

[1] D.W. Chan, M.M. Kumarasawamy, A comparative study of causes of time overruns in Hong Kong construction projects, International Journal of Project Management 15 (1997) 55-63.

[2] W. Baker, H. Reid, Identifying and Managing Risk, French Forest, Pearson Education, USA, 2005.

[3] D. Hillson, Use a RBS (risk breakdown structure) to understand your risks, in: Proceedings of the Project Management Institute Annual Seminars \& Symposium, San Antonio, TX, USA, Oct. 3-10, 2002.

[4] A Guide to the Project Management Body of Knowledge (PMBOK ${ }^{\circledR}$ Guide), 2nd ed., Project Management Institute, 2000.

[5] R. Mehdizadeh, Dynamic and multi-perspective risk management of construction projects using tailor-made risk breakdown structures, Ph.D. Thesis, Bordeaux University, France, 2012.

[6] R. Mehdizadeh, D. Breysse, F. Taillandier, H. Niandou, Advanced methodology of risk breakdown structure developing for risk management of tunneling and construction projects, in: 29th University Meeting of 
Civil Engineers, University AbouBekr Belkaid, Tlemcen, Algeria, 2011, pp. 3-89.

[7] W.D. Rowe, An Anatomy of Risk, John Wiley \& Sons Inc., New York, USA, 1977.

[8] R. Flanagan, G. Norman, Risk Management and Construction, Wiley, Australia, 1993.

[9] IEC 62198, International Standard IEC 62198:2001, International Electro technical Commission, 2001.

[10] Project Risk Management Guidance for WSDOT Projects, Washington State Department of Transportation, 2010.

[11] A Guide to the Project Management Body of Knowledge (PMBOK® Guide), 3rd ed., Project Management Institute, 2004.

[12] J. Keci, A. Oztas, Investigation on risk management implementation in Albanian construction industry, in: Proceedings of the First International Conference in Architecture and Urban Design, Tirana, Albania, 2012.

[13] Risk Management Reports[Online], 1999, www.riskinfo.com (accessed on June 13, 2013).

[14] D. Berkeley, P.C. Humphreys, R.D. Thomas, Project risk action management, Construction Management and Economics 9 (1991) 3-17.

[15] D. Baloi, A.D.F. Price, Modeling global risk factors affecting construction cost performance, International Journal of Project Management 21 (2003) 261-269.

[16] AS/NZS 4360, Australian/New Zealand Standard on Risk Management, Standards Australia and Standards New Zealand, 2004.

[17] AS/NZS ISO 31000:2009, Australian/New Zealand Standard on Risk Management, Standards Australia and Standards New Zealand, 2009.

[18] S. Baker, D. Ponniah, S. Smith, Risk response techniques employed currently for major projects, Construction Management and Economics 17 (1999) 205-213.

[19] S.Q. Wang, M.F. Dulaimi, M.Y. Aguria, Risk management framework for construction projects in developing countries, Construction Management and Economics 22 (2004) 237-252.

[20] H. Zhou, H. Zhang, Dynamic risk management system for large project construction in China, in: The Proceeding of American Society of Civil Engineers, West Palm Beach, Florida, 2010, pp. 202-202.

[21] A. del Cano, M. pilar de la Cruz, Integrated methodology for project risk management, Journal of Construction Engineering and Management 11-12 (2002) 473-485.

[22] R.J. Chapman, The controlling influences on effective risk identification and assessment for construction design management, International Journal of Project Management 19 (2001) 147-160.

[23] S. Ebrahimnejad, S.M. Mousavi, H. Seyrafianpour, Risk identification and assessment for build-operate-transfer projects: A fuzzy multi attribute decision making model, Expert Systems with Applications 37 (2010) 575-586.

[24] S.M. el Sayegh, Risk assessment and allocation in the UAE construction industry, International Journal of Project Management 26 (2008) 431-438.

[25] J.H.M. Tah, V. Carr, Towards a framework for project risk knowledge management in the construction supply chain, Advances in Engineering Software 32 (2001) 835-846.

[26] D.C. Cooper, C.B. Chapman, Risk Analysis for Large Projects: Models, Methods, and Cases, Wiley, 1987.

[27] P.X.W. Zou, G. Zhang, J. Wang, Understanding the key risks in construction projects in China, Int. J. of Project Management 25 (2007) 601-614.

[28] V.W.Y. Tam, L.Y. Shen, C.M. Tam, W.W.S. Pang, Investigating the intentional quality risks in public foundation projects: A Hong Kong study, Building and Environment 42 (2007) 330-343.

[29] A Guide to the Project Management Body of Knowledge (PMBOK ${ }^{\circledR}$ Guide), Project Management Institute, 4th ed., 2008.

[30] C. Chapman, Project risk analysis and management-PRAM: The generic process, International Journal of Project Management 15 (1997) 273-281.

[31] A.S. Akintoye, M.J. MacLeod, Risk analysis and management in construction, International Journal of Project Management 15 (1) (1997) 31-38.

[32] N.N. Hlaing, D. Singh, R.L.K. Tiong, M. Ehrlich, Perceptions of Singapore construction contractors on construction risk identification, Journal of Financial Management of Property and Construction 13 (2008) 85-95.

[33] S. Simister, Usage and benefits of project risk analysis and management, International Journal of Project Management 12 (1998) 5-8.

[34] V. Holzmann, I. Spiegler, Developing risk breakdown structure for information technology organizations, International Journal of Project Management 29 (5) (2011) 536-547.

[35] D. Hillson, S. Grimaldi, C. Rafele, Managing project risks using cross risk breakdown matrix, Risk Management 8 (2006) 61-76. 